\title{
Single dose epidural hydromorphone in labour pain: maternal pharmacokinetics and neonatal exposure
}

\author{
Terhi Puhto $^{1}$ (D) Merja Kokki $^{2} \cdot$ Henriikka Hakomäki $^{3} \cdot$ Michael Spalding $^{1} \cdot$ Teemu Gunnar $^{4} \cdot$ Seppo Alahuhta $^{1}$. \\ Merja Vakkala ${ }^{1}$
}

Received: 12 December 2019 / Accepted: 24 April 2020 / Published online: 3 May 2020

(C) The Author(s) 2020

\begin{abstract}
Introduction Epidural hydromorphone could be useful in obstetric analgesia as there is a need for a more water-soluble opioid than sufentanil or fentanyl with prolonged analgesic effect. To our knowledge, the pharmacokinetics of epidural hydromorphone has not been evaluated in parturients.

Materials and methods In this pilot study, seven healthy parturients were given a single epidural dose of hydromorphone for labour pain. One parturient received $1.5 \mathrm{mg}$, two $0.75 \mathrm{mg}$ and four $0.5 \mathrm{mg}$ of hydromorphone hydrochloride. Dose was decreased due to nausea and pruritus. Hydromorphone's effect, adverse effects and plasma concentrations were evaluated. Neonatal drug exposure was evaluated by umbilical vein and artery opioid concentration at birth. Neonatal outcomes were assessed using Apgar and the Neurologic Adaptive Capacity Score (NACS).

Results All patients received additional levobupivacaine doses on parturients' requests. The first dose was requested at a median of $163 \mathrm{~min}$ (range 19-303 $\mathrm{min}$ ) after hydromorphone administration. A total of 12 opioid related expected adverse events were reported by seven parturients. All newborn outcomes were uneventful. Hydromorphone's distribution and elimination after single epidural dose seem similar to that reported for non-pregnant subjects after intravenous hydromorphone administration, but further research is required to confirm this observation.

Conclusions The optimal dose of hydromorphone in labour pain warrants further evaluation.
\end{abstract}

Keywords Hydromorphone $\cdot$ Pharmacokinetics $\cdot$ Epidural $\cdot$ Labour $\cdot$ Pain

\section{INRODUCTION}

Labour pain is severe in $80 \%$ of parturients [1]. Epidural analgesia with bolus doses of local anaesthetics and opioid analgesics is commonly used for pain relief [2]. Lipid soluble opioids, fentanyl and sufentanil, are preferred as

Terhi Puhto

terhi.puhto@ppshp.fi

1 Department of Anaesthesiology, Medical Research Center Oulu (MRC Oulu), Oulu University Hospital, PO Box 21, 90029 Oulu, Finland

2 Department of Anaesthesiology and Intensive Care, Kuopio University Hospital, Kuopio, Finland

3 School of Pharmacy, University of Eastern Finland, Kuopio, Finland

4 Forensic Toxicology Unit (THL), The Finnish Institute for Health and Welfare, Helsinki, Finland the onset of analgesic action is rapid. However, the short duration of effect necessitates repeated dosing [3]. Thus, in prolonged deliveries, the cumulative dose of opioid may become unnecessarily high and may cumulate into the foetus [4].

Lipid solubility of an opioid is one of the most important attributes for onset and duration of analgesia [5]. Very lipid soluble opioids given intrathecally absorb rapidly through the epidural fat into the circulation [3], but probably partially act on the spinal opioid receptors [6]. Lipophobic opioids proceed easier from epidural space to intrathecal space and remain in the cerebrospinal fluid (CSF) longer than lipophilic opioids [6]. Lipophobic opioids exert an analgesic effect at significantly lower doses after spinal administration than they will after intravenous administration. Lipophobic morphine has been evaluated in labour pain, but its slow onset of action, adverse effects and the possibility of late onset respiratory depression makes it less attractive for spinal administration in labour pain treatment [7]. 
Hydromorphone (HM) is a semisynthetic, selective $\mu$-opioid receptor agonist that was synthesisedsynthesized in 1922 and introduced for clinical use in 1926. HM is a hydrogenated ketone of morphine and is chemically categorized as a phenanthrene [8]. The safety of HM in epidural use has been evaluated in several clinical trials [9], and it has been proposed that the use of intrathecal morphine can be replaced with HM [10]. HM's onset of analgesia begins $20 \mathrm{~min}$ after epidural dosing and analgesia after a single dose lasts for up to 16-24 $\mathrm{h}$ [11-13].

Hydromorphone is extensively metabolized to hydromorphone-3-glucuronide and dihydroisomorphine glucuronide by hepatic UDP-Glucuronosyltransferase-2B7-enzyme (UGT2B7) [8]. Hydromorphone-3-glucuronide is an active metabolite that may cause neuroexcitatory effects; however, this has not been well-documented in humans and is expected to only have clinical relevance in patients with renal impairment. Genetic polymorphisms have been described for UGT2B7 and may play a role in interindividual variability of HM clearance [14]. To our knowledge, the elimination of HM has not been studied in neonates. However, Bouwmeester and associates have reported low formation of morphine-3-glucuronide in neonates during their first days of life, glucuronidation process also mediated by UGT2B7 [15]. This finding suggests immature glucuronidation of HM in the neonate, leading to low elimination of the parent drug. The median protein binding of hydromorphone is low $12 \%$ [16]; therefore plasma protein changes that occur during pregnancy may not have so much effect on hydromorphone pharmacokinetics or -dynamics.

Epidural HM could be useful in obstetric analgesia as there is a need for a more water-soluble opioid than sufentanil or fentanyl with prolonged analgesic effect. To our knowledge, the pharmacokinetics of HM has not been evaluated after epidural use in parturients. Thus, we have designed the present study to assess the pharmacokinetics, efficacy and safety of $\mathrm{HM}$ in labouring patients as well as its effects on the newborn.

\section{Materials and methods}

The study protocol was approved by the Finnish Research Ethics Board approval (TUKIJA) (Dnro 92/06.00.01/2016) and conducted in accordance with the Declaration of Helsinki. The Finnish Medicines Agency was notified (KL nro 119/2016, 07.10.2016), and the study was recorded in the European Clinical Trials Database (EudraCT no. 2016000903-10). The study had institutional approval.

Parturients were recruited between February 2017 and February 2018. Inclusion criteria were singleton pregnancy, American Society of Anesthesiologists (ASA) I/II physical status, term pregnancy (gestational weeks between 37 and 41), maternal age 18 years or older, maternal wish to have epidural analgesia and informed consent. Exclusion criteria were no informed consent, foetal growth retardation or placental insufficiency, contraindication to epidural analgesia or to HM, body mass index (BMI) over $35 \mathrm{~kg} / \mathrm{m}^{2}$, immediate need for pain relief or opioid use during the last $12 \mathrm{~h}$.

Women were asked to participate in early labour when their contraction pain was less than 5 on an 11-point numeric rating scale $(\mathrm{NRS}, 0=$ no pain, $10=$ most pain). The parturients were provided oral and written information on the trial protocol, and the parturients gave their written informed consent. When parturients wished to have epidural analgesia, an epidural catheter was placed via the lumbar 2-3 or 3-4 interspace using a paramedial approach and loss of resistance to saline. To ensure epidural catheter placement, a test dose of $10 \mathrm{~mL}$ lidocaine $5 \mathrm{mg} / \mathrm{mL}$ with epinephrine $10 \mu \mathrm{g} / \mathrm{mL}$ was given, and loss of cold sensation was tested with an alcohol swipe. Dose of HM was chosen based on earlier studies [11-13]. Hydromorphone hydrochloride $1.5 \mathrm{mg}$ (corresponding to $1.33 \mathrm{mg}$ of HM free base) was administered epidurally to the first patient, $0.75 \mathrm{mg}(0.665 \mathrm{mg}$ of $\mathrm{HM}$ free base $)$ to the next two patients and $0.5 \mathrm{mg}$ ( $0.443 \mathrm{mg}$ of HM free base) to four successive patients (Palladon ${ }^{\circledR} 2 \mathrm{mg} / \mathrm{mL}$, preservative free, Mundipharma, Vantaa, Finland) mixed with $10 \mathrm{~mL} \mathrm{sa}-$ line. The dose was decreased progressively as the higher doses were associated with protracted nausea. Levobupivacaine $1.25 \mathrm{mg} / \mathrm{mL} 10 \mathrm{~mL}$ was used as a rescue medication if the patient required additional pain relief. Maternal blood pressure, heart rate, peripheral oxygen saturation and foetal heart rate using cardiotocography and uterine contractions were monitored. Cardiotocography recordings were evaluated during labour by an attending gynaecologist who performed further procedures (e.g. intrapartum foetal $\mathrm{pH}$ measurement) if necessary.

An intravenous cannula for blood sampling was inserted in an antecubital vein. Venous blood samples were taken at 0,15 , 30 and $45 \mathrm{~min}$, and at $1,2,3,4,6,8,10$ and $12 \mathrm{~h}$ after the epidural HM dosing or until the mother gave birth. The last maternal blood sample was obtained immediately after birth. Umbilical arterial and venous blood samples were drawn after delivery after the umbilical cord had been clamped to estimate the neonatal drug exposure.

Neonatal outcome was assessed using Apgar scores [17] at 1,5 and $10 \mathrm{~min}$ after birth and the Neurologic and Adaptive Capacity Score (NACS) [18] at 30-60 min after birth. A baby with a score of 35 or more is considered to be a vigorous neonate [18].

\section{Hydromorphone laboratory analysis}

Blood samples were collected into BD Vacutainer® $\mathrm{K}_{2}$ EDTA tubes (reference \#368841/2 ml) and stored at $-21{ }^{\circ} \mathrm{C}$ until analysis. HM hydrochloride was purchased from Sigma (St. Louis, MO, USA), and a deuterium-labelled HM-d6 solution $(0.1 \mathrm{mg} / \mathrm{mL}$ in $\mathrm{MeOH})$ was obtained from Cerilliant (Round Rock, Texas, USA) for analytical reference compounds. All solvents and other reagents of analytical grade were supplied by Merck (Darmstadt, Germany) or VWR International 
(Fontenay-sous-Bois, France). All HM determinations were performed at the Forensic Toxicology Unit in the National Institute for Health and Welfare, Helsinki, Finland.

In analytical sample preparation, $0.5 \mathrm{~mL}$ of $0.5 \mathrm{M}$ $\mathrm{Na}_{2} \mathrm{HPO}_{4}$ buffer ( $\mathrm{pH} 9.8$ ) and $3 \mathrm{~mL}$ of n-butyl acetate/ ethylacetate $(1: 1, \mathrm{v} / \mathrm{v})$ including $0.05 \mu \mathrm{L}$ of HM-d6 $(0.1 \mathrm{mg} /$ $\mathrm{mL}$ in $\mathrm{MeOH}$ ) were added to $0.5 \mathrm{~mL}$ of whole blood. The contents of the test tubes were rapidly and simultaneously vortex-mixed ( $30 \mathrm{~s})$ in a multitube vortexer. After centrifugation $(2500 \mathrm{~g}, 5 \mathrm{~min}), 60 \mu \mathrm{L}$ of the supernatant were added to $2.0 \mathrm{~mL}$ autosampler vials containing $200 \mu \mathrm{L}$ inserts. The samples were rapidly vortex-mixed ( $1 \mathrm{~s}$ ) and capped for analytical determination.

Blood HM concentrations were determined using an Agilent Technologies (Palo Alto, CA, USA) 1290 II ultrahigh-performance liquid chromatography (UHPLC) coupled with a 6495A triple quadrupole mass spectrometer (MS/MS). Electrospray ionization in positive mode (ESI+) with a heated nitrogen gas (98\%) was applied for ionization. An in-house developed method was linear from 0.1 to $25 \mathrm{ng} / \mathrm{mL}$ of $\mathrm{HM}$, and the lower limit of quantification (LLOQ) of HM was $0.1 \mathrm{ng} / \mathrm{mL}$. Concentrations below $0.1 \mathrm{ng} / \mathrm{mL}$ were reported as less than LLOQ. Accuracy (bias), repeatability (withinday precision) and time-different intermediate precision (day-to-day precision) were always below $15 \%$ for three different concentration levels $(0.2 ; 1 ; 10 \mathrm{ng} / \mathrm{mL})$ at the validation experiments (three replicates each day for each concentration $\times 5$ days).

No interfering compounds or any selectivity problems were observed. Standard calibration curves of HM were prepared for each analysis batch, and HM-d6 was used in all analyses and daily calibration as an internal standard.

\section{Hydromorphone pharmacokinetic analysis}

The results are expressed as HM free base. Pharmacokinetic parameters were calculated based on a noncompartmental analysis method, using Phoenix WinNonlin software version 6.3 (Certara, Princeton, NJ, USA). The elimination rate constant (kel) was determined from the terminal log-linear phase using 4-7 data points. The terminal half-life ( $t 1 / 2)$ was calculated as $\ln (2) / \mathrm{kel}$. Other determined pharmacokinetic parameters were the maximum observed plasma concentration (Cmax) and time to maximum observed plasma concentration (Tmax), area under the concentration-time curve from time 0 to the last quantifiable concentration using the linear trapezoidal rule (AUClast), area under the curve from time 0 extrapolated to infinity (AUCinf), the percentage of the extrapolated area (AUCextrap), the apparent volume of distribution at the terminal phase $(\mathrm{Vz} / \mathrm{F})$ and the apparent total body clearance $(\mathrm{CL} / \mathrm{F})$. Because three different doses were used, the pharmacokinetic parameters were normalized by the dose for Cmax and the AUCs.
Pharmacokinetic simulation of epidural hydromorphone administration was performed using pharmacokinetic parameters (apparent volume of the central compartment $\mathrm{Vc} 26.2 \mathrm{~L}$, elimination rate constant from the central compartment k10 $0.071 \mathrm{~min}^{-1}$, and intercompartmental transfer rate constants k12 $0.260 \min ^{-1}, \mathrm{k} 210.110 \min ^{-1}, \mathrm{k} 130.153 \mathrm{~min}^{-1}, \mathrm{k} 31$ $0.017 \mathrm{~min}^{-1}$ ) from a previous i.v. study [17] (dose $10 \mu \mathrm{g} / \mathrm{kg}$, mean dose of $0.73 \mathrm{mg}$ in the study population), and additionally adjusting the absorption rate constant $\left(\mathrm{k}_{\mathrm{a}}\right)$ of epidural hydromorphone to $0.015 \mathrm{~min}^{-1}$ to get the observed Tmax, and assuming that the absolute bioavailability was $100 \%$. Simulated doses $0.50 \mathrm{mg}$ and $0.75 \mathrm{mg}$ were chosen based on doses used in the present study. Simulation was conducted with delta time of 2 min and Runge-Kutta 4th order algorithm using STELLA Professional software (version 1.1, isee systems Inc. NH, USA).

\section{Statistical analysis}

No formal sample size calculation was performed, but a group of seven parturients was considered to provide sufficient pharmacokinetic data for this pilot study of epidural HM.

The results are presented as median, minimum and maximum or number of parturients as appropriate. The ratios of venous versus arterial umbilical cord drug concentrations were calculated. The Wilcoxon signed-rank test was used to determine whether the ratio was significantly different from unity.

\section{Results}

Seven women aged 22-34 years, agreed to participate. Data regarding the parturients' demographics, as well as pregnancy- and labour-related details are presented in Table 1.

There was one major protocol deviation during the study. Due to protracted nausea and vomiting, the dose of HM was eventually decreased from 1.5 to $0.5 \mathrm{mg}$. A few minor deviations regarding the planned sampling times were also noted. As the actual sampling times were used in the pharmacokinetic calculations, it was considered unlikely that these deviations affected the results. One parturient who had received a dose of $0.75 \mathrm{mg}$ epidurally did not give birth during the $730 \mathrm{~min}$ follow-up, and caesarean section due to failure of labour progress and chorioamnionitis was performed $24 \mathrm{~h}$ and $55 \mathrm{~min}$ after HM administration (Table 1, patient ID 2).

HM maternal plasma concentrations are presented in Fig. 1 and pharmacokinetic parameters expressed for HM free base in Table 2. ID1 showed high HM concentrations throughout the sampling period, thus accurate AUCs, $\mathrm{T}^{1 / 2}, \mathrm{Vz} / \mathrm{f}$ and $\mathrm{CL} / \mathrm{F}$ estimates could not be calculated for this individual. As three different doses were used over the course of the study, a dosenormalized Cmax and AUCs were calculated for 
Table 1 Parturients' age, weight and height, pregnancy- and labour-related details

ID Age (years) Weight $(\mathrm{kg})$ Height $(\mathrm{cm})$ Gestational age (weeks) Duration of the first Duration of the second Vaginal delivery/caesarian secstage (hh:min) stage (min) tion

\begin{tabular}{llllllll}
\hline $\mathbf{1}$ & 22 & 63 & 160 & 41 & $11: 33$ & 5 & Yes $/$ no \\
$\mathbf{2}$ & 31 & 94 & 168 & 40 & - & - & No/yes \\
$\mathbf{3}$ & 29 & 82 & 165 & 42 & $5: 50$ & 11 & Yes $/$ no \\
$\mathbf{4}$ & 23 & 69 & 164 & 40 & $14: 10$ & 17 & Yes/no \\
$\mathbf{5}$ & 33 & 85 & 166 & 37 & $9: 45$ & 20 & Yes $/$ no \\
$\mathbf{6}$ & 24 & 68 & 167 & 39 & $22: 00$ & 56 & Yes $/$ no \\
7 & 28 & 82 & 173 & 39 & $21: 10$ & 28 & Yes $/$ no \\
\hline
\end{tabular}

ID, Identification number of the patient; hh:min, hours and minutes

Definition of the 1st stage: cervix attains full dilation and the presenting foetal part descends

Definition of the 2 nd stage: active pushing

interindividual comparison. Dose-normalized (per mg of HM free base) median Cmax was $2.44 \mu \mathrm{g} / \mathrm{L} / \mathrm{mg}$ (range 2.15$3.57 \mu \mathrm{g} / \mathrm{L} / \mathrm{mg}$ ), AUClast $487 \mathrm{~min} \mu \mathrm{g} / \mathrm{L} / \mathrm{mg}$ (range 369$713 \mathrm{~min} \mu \mathrm{g} / \mathrm{L} / \mathrm{mg}$ ) and AUCinf $619 \mathrm{~min} \mu \mathrm{g} / \mathrm{L} / \mathrm{mg}$ (range 453-938 $\mathrm{min} \mu \mathrm{g} / \mathrm{L} / \mathrm{mg}$ ). The relative standard deviations of dose-normalized Cmax, AUClast and AUCinf were 23\%, $27 \%$ and $28 \%$, respectively. The plasma concentration curve of epidural HM (bioavailability 100\%) was simulated using distribution and elimination kinetics from a previously published i.v. study [19], and the simulated curves for doses $0.50 \mathrm{mg}$ and $0.75 \mathrm{mg}$ showed similarity to the observed curves in the present study in parturients (Fig. 2).

Epidural HM was given a median of 10 min (range 5-18) after the $10 \mathrm{~mL}$ test dose of lidocaine $5 \mathrm{mg} / \mathrm{mL}$ with adrenaline $10 \mu \mathrm{g} / \mathrm{mL}$. All patients received additional levobupivacaine doses. The first dose was requested at a median of 163 min (range 19-303) after HM administration. Levobupivacaine was given on patient's request. Contraction pain ratings and doses of levobupivacaine given are presented in Fig. 1. Three patients received only one subsequent dose of levobupivacaine, even though each of them had been administered a different dose of HM. Two parturients had two doses of levobupivacaine, and they had received the HM $0.5 \mathrm{mg}$. One participant required four doses of levobupivacaine over time period of $409 \mathrm{~min}$ and one had five doses over $730 \mathrm{~min}$. Two doses of levobupivacaine were given prior to the HM onset of action, at $19 \mathrm{~min}$ after HM. The duration of delivery after receiving HM was a median of 385 min (range 229-552) in the six patients who delivered vaginally.

Twelve adverse effects were reported by seven parturients. The most common adverse effects were nausea $(n=5)$, vomiting $(n=3)$, pruritus $(n=3)$ and hypotension $(n=1)$. Patients ID 5 and ID 7 (both had HM $0.44 \mathrm{mg}$ ) suffered prolonged pruritus, which began from 3.6 to $4.3 \mathrm{~h}$ after receiving HM. Patient ID 1 (HM1.33 mg) suffered protracted nausea that began after delivery and was clearly an adverse effect of
HM. Patients ID 2 (HM $0.67 \mathrm{mg}$ ), 3 (HM $0.67 \mathrm{mg}$ ), 5 (HM $0.44 \mathrm{mg}$ ) and 6 (HM $0.44 \mathrm{mg}$ ) had nausea prior to HM dosing, as well as briefly after HM administration.. Patient ID 4 (HM $0.44 \mathrm{mg}$ ) vomited ones $440 \mathrm{~min}$ after receiving $\mathrm{HM}$ without having any nausea and had mild pruritus. Hypotension, with a systolic pressure of $87 \mathrm{mmHg}$ was treated with $3 \mathrm{mg}$ boluses of ephedrine. None of the parturients experienced respiratory depression, and no supplemental oxygen was needed.

Our results suggest that $\mathrm{HM}$ crosses the placenta into the foetus as has been shown to other opioids [20]. Apgar and NAC scores of the newborns and HM concentrations in the umbilical artery and vein are presented in Table 3. A foetal/ maternal-ratio (F/M-ratio) for HM concentrations was calculated from four parturients whose HM concentrations were above the lower limit of quantification. One newborn had an umbilical venous-HM concentration of $0.11 \mu \mathrm{g} / \mathrm{L}$ and in the mother's plasma $<0.1 \mu \mathrm{g} / \mathrm{L}$, i.e. F/M ratio would have been $>$ 1.1. In six out of seven cases, the NACS was performed 30 min after birth. In one newborn, NACS was 30 and an Apgar score of 7/9/9. This newborn (ID 6) was born utilizing a vacuum extraction, remained under supervision of midwives, and further recovery of the baby was uneventful. None of the newborns required paediatric interventions.

\section{Discussion}

In the present study of labouring women, after epidural HM administration the median elimination half-life of $162 \mathrm{~min}$

Fig. 1 a Hydromorphone (HM) plasma concentrations from seven parturients plotted against time after epidural administration of $0.5-1.5 \mathrm{mg}$ of hydromorphone. $\mathbf{b}-\mathbf{h}$ Individual hydromorphone plasma concentrations, NRSs (numeric rating scale for pain), times of birth and levobupivacaine administrations plotted against time from study participants ID $1-7$ 

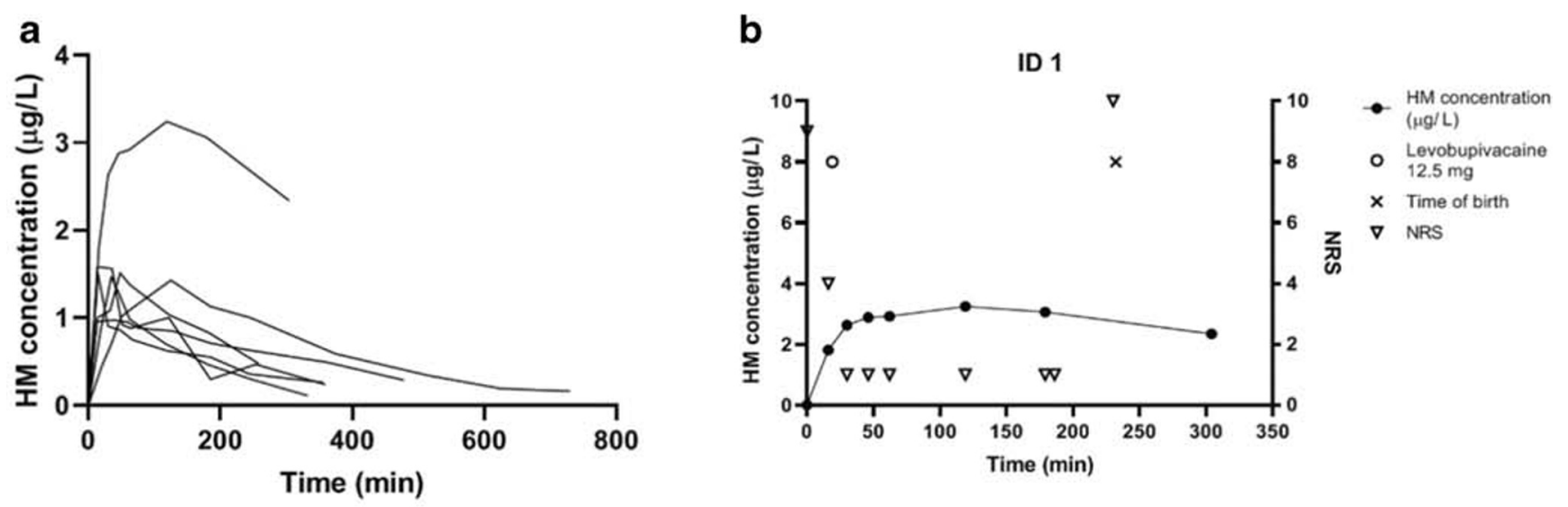

C

ID 2

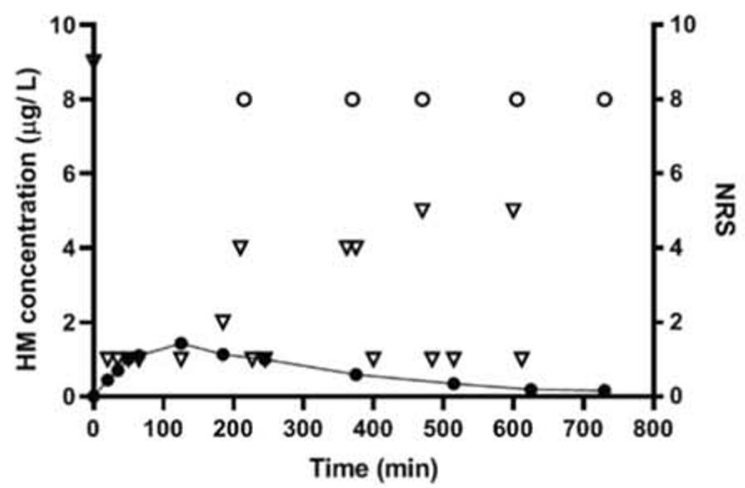

e

ID 4

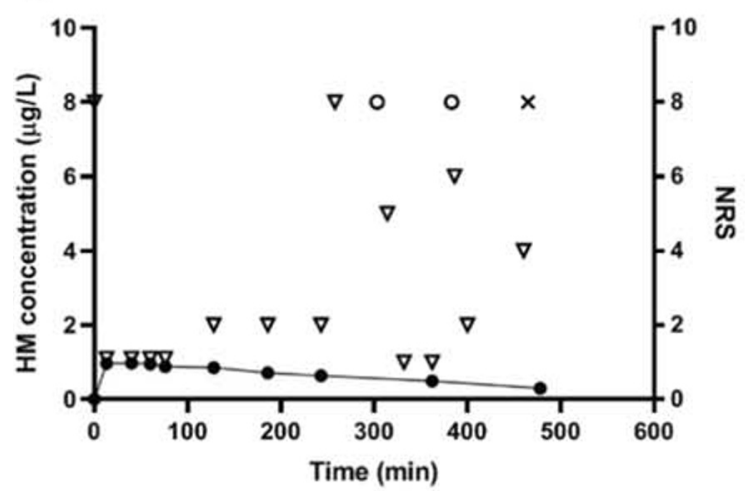

g

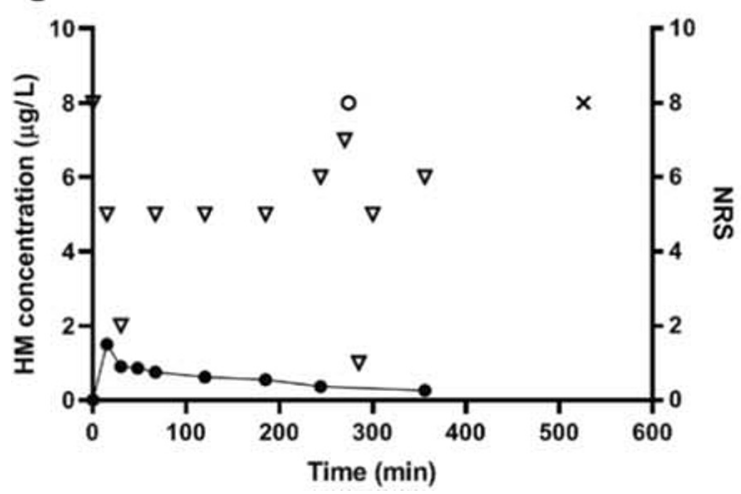

d

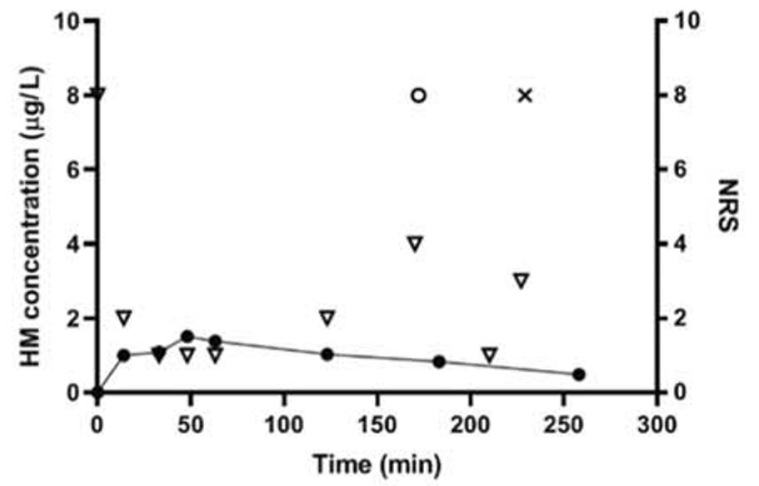

f

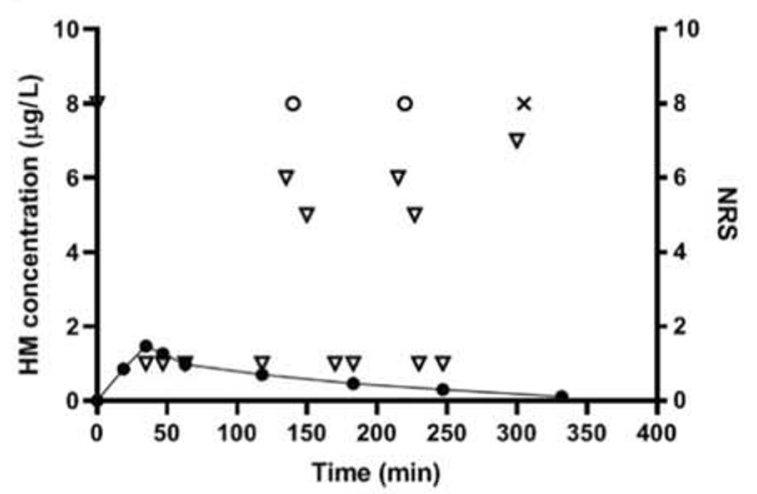

h

ID 7

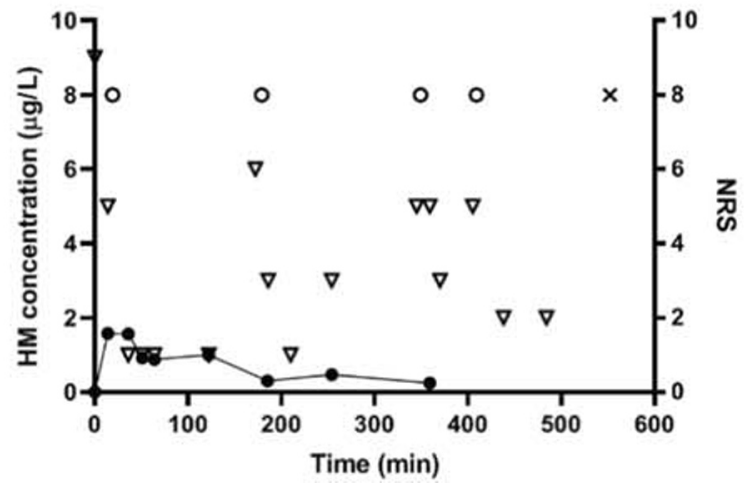



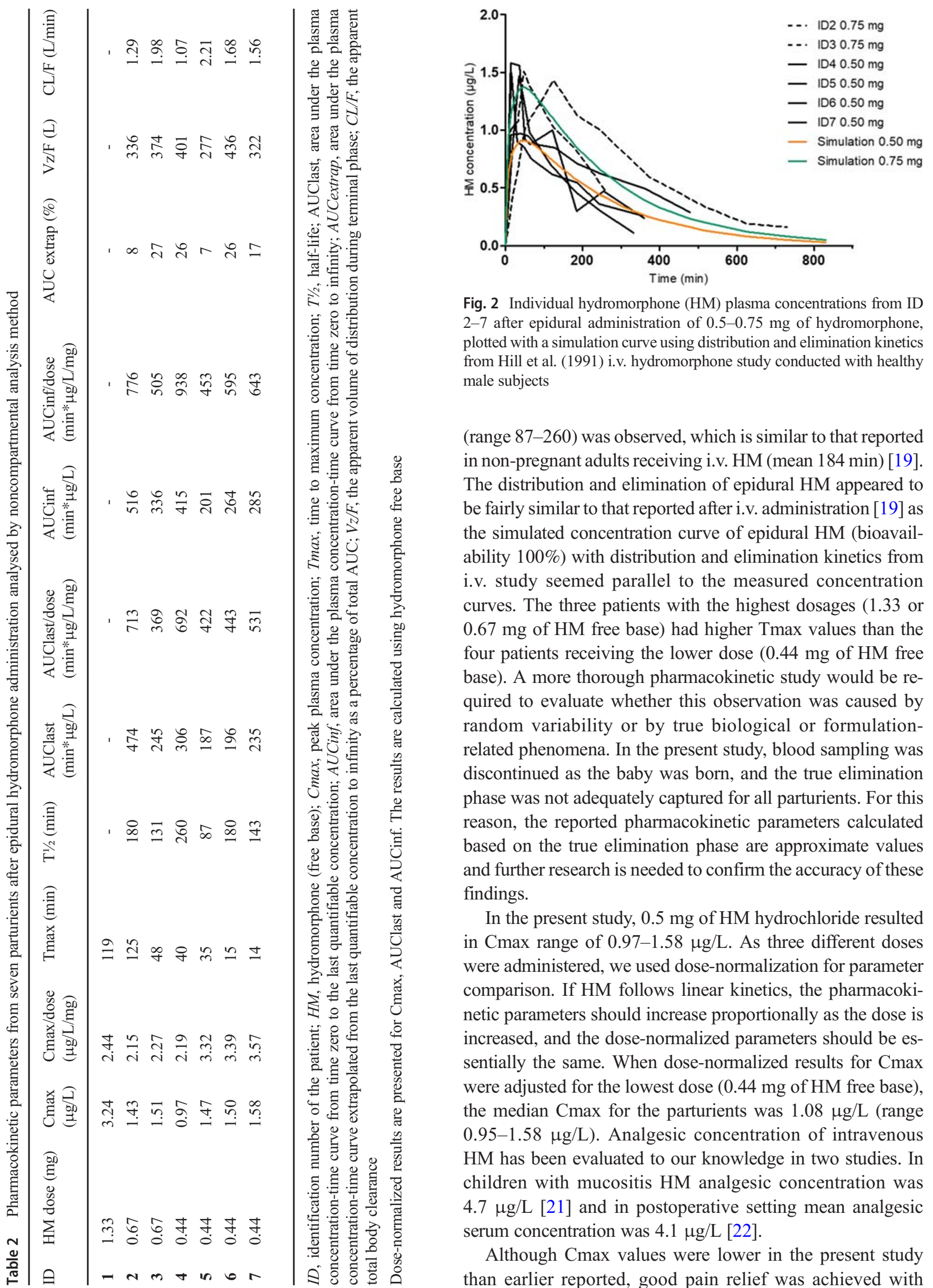

Fig. 2 Individual hydromorphone (HM) plasma concentrations from ID 2-7 after epidural administration of $0.5-0.75 \mathrm{mg}$ of hydromorphone, plotted with a simulation curve using distribution and elimination kinetics from Hill et al. (1991) i.v. hydromorphone study conducted with healthy male subjects

(range 87-260) was observed, which is similar to that reported in non-pregnant adults receiving i.v. HM (mean $184 \mathrm{~min}$ ) [19]. The distribution and elimination of epidural HM appeared to be fairly similar to that reported after i.v. administration [19] as the simulated concentration curve of epidural HM (bioavailability 100\%) with distribution and elimination kinetics from i.v. study seemed parallel to the measured concentration curves. The three patients with the highest dosages ( 1.33 or $0.67 \mathrm{mg}$ of HM free base) had higher Tmax values than the four patients receiving the lower dose $(0.44 \mathrm{mg}$ of $\mathrm{HM}$ free base). A more thorough pharmacokinetic study would be required to evaluate whether this observation was caused by random variability or by true biological or formulationrelated phenomena. In the present study, blood sampling was discontinued as the baby was born, and the true elimination phase was not adequately captured for all parturients. For this reason, the reported pharmacokinetic parameters calculated based on the true elimination phase are approximate values and further research is needed to confirm the accuracy of these findings.

In the present study, $0.5 \mathrm{mg}$ of HM hydrochloride resulted in Cmax range of $0.97-1.58 \mu \mathrm{g} / \mathrm{L}$. As three different doses were administered, we used dose-normalization for parameter comparison. If HM follows linear kinetics, the pharmacokinetic parameters should increase proportionally as the dose is increased, and the dose-normalized parameters should be essentially the same. When dose-normalized results for Cmax were adjusted for the lowest dose ( $0.44 \mathrm{mg}$ of HM free base), the median Cmax for the parturients was $1.08 \mu \mathrm{g} / \mathrm{L}$ (range $0.95-1.58 \mu \mathrm{g} / \mathrm{L})$. Analgesic concentration of intravenous HM has been evaluated to our knowledge in two studies. In children with mucositis HM analgesic concentration was $4.7 \mu \mathrm{g} / \mathrm{L}[21]$ and in postoperative setting mean analgesic serum concentration was $4.1 \mu \mathrm{g} / \mathrm{L}$ [22].

Although Cmax values were lower in the present study than earlier reported, good pain relief was achieved with 


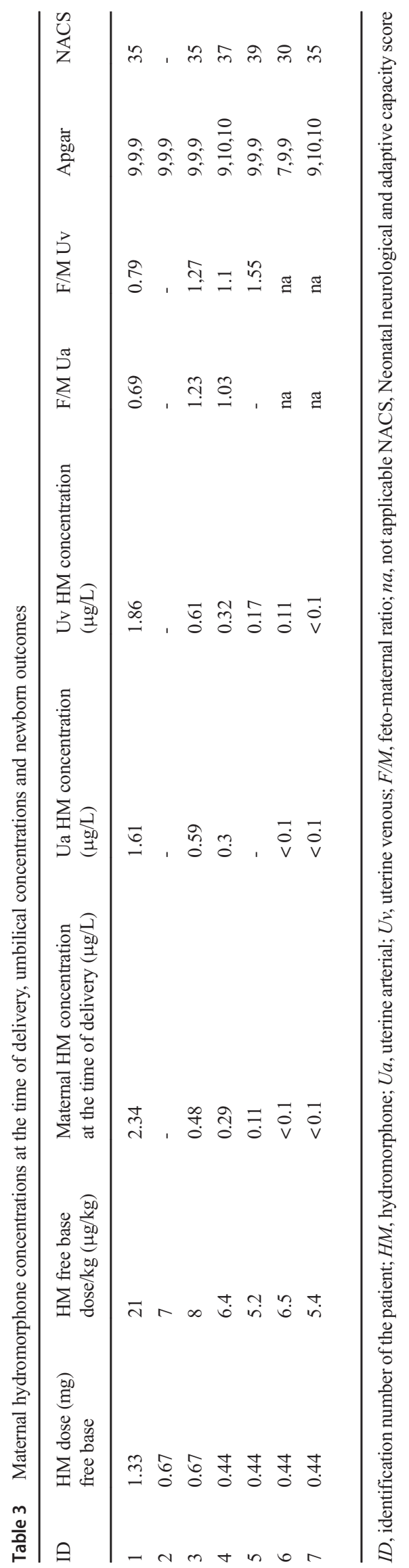

combination of local anaesthetic and HM. Plasma analgesic concentrations of HM after intravenous dosing are not comparable with plasma concentrations after epidural dosing as plasma concentration of HM depends on the rate of leaking from the epidural environment, as well as from the clearance of HM from the plasma, of which both are variable. Despite the low Cmax after epidural dosing, this could be perceived as evidence of HM's spinal site of action when given epidurally.

Epidural HM pharmacokinetics has been studied in 16 thoracotomy patients [23]. In a study by Brose and co-workers, $0.75 \mathrm{mg} \mathrm{HM}$ was co-administered with $5 \mathrm{mg}$ of morphine to a lumbar epidural catheter for postoperative pain relief. The mean HM Cmax of $14 \mu \mathrm{g} / \mathrm{L}$ was observed after 8 min and plasma $\mathrm{HM}$ concentrations remained at $5 \mu \mathrm{g} / \mathrm{L}$ or higher after $4 \mathrm{~h}$ [23]. These concentrations are much higher than in the present study despite similar dosing in two parturients. This might be an effect of the epinephrine administered in our test dose, which was administered 5-18 min prior to the HM and could slow HM migration into the systemic circulation [24]. In addition, the larger circulating plasma volume in pregnant than in non-pregnant patients may result changes in HM distribution. The glucuronidation of HM in pregnancy should be similar than in non-pregnant patients as UGT2B7 activity is unaltered during pregnancy based on zidovudine and morphine pharmacokinetic data [25]. Renal elimination of hydromorphone-3- glucuronide should be increased as maternal glomerular filtration rate increases during pregnancy. However low formation of metabolite of morphine by UGT2B7, morphine-3-glucuronide in neonates during their first days of life, has been reported [15]. This suggests immature glucuronidation of $\mathrm{HM}$ in the neonate that have to be considered when hydromorphone in labour analgesia is used. However, glomerular filtration rate in the neonates increases approximately $15 \%$ at birth and this increases slightly elimination of morphine and paracetamol [26], but we did not find data about hydromorphone elimination in newborns.

The adverse events in the present study were common to spinal opioids [5]. No severe adverse events occurred, none of the parturients in the present study had peripheral oxygen saturation less than $97 \%$ and none of them needed supplemental oxygen during the $12 \mathrm{~h}$ of observation. Lipophilic intrathecal sufentanil has been demonstrated to cause respiratory depression within 20 min due to its rapid rostral spread [3,27]. We measured neither carbon dioxide concentrations nor respiratory rate, which might have been more sensitive methods than peripheral oxygen saturation [28].

The newborns had good Apgar scores. In five newborns, NACS was 35 or higher, but one had a NACS of 30 at $180 \mathrm{~min}$ after birth. The recovery of this newborn was uneventful. Foetal/maternal HM-ratio was less than unity in one case, ratio 0.8 , and higher than 1.1 in three cases, suggesting that $\mathrm{HM}$ may accumulate into the foetus. However, differences in the pattern of clearance from the maternal circulation, transfer 
across the placenta, and clearance within the foetus, the ratio can vary widely depending on the time interval at which the last dose was administered to the mother. The ratio depends on the clearance capacity of the foetus which is low due to immature glucuronidation function in the liver, the rate of transport from foetal to maternal side over the placenta and the clearance rate of mother. The placental transport of drugs is affected by protein binding and ionization of the drug, free, non-ionized drug is transferred easily through placenta. As foetus is slightly acidic compared with mother ionization of drug may cause higher foetal concentrations of HM and may be reason to F/M ratio higher than 1 in the present study. However, F/M ratio could only be calculated in four out of seven parturients and this observation warrants further evaluation. Physiologically based pharmacokinetic (PBPK) modelling is increasingly used in pregnant patients due to certain limitations of traditional pharmacokinetic analysis. Paracetamol, another UGT substrate, has been evaluated with PBPK modelling and the developed pregnancy PBPK models successfully predicted pharmacokinetics of paracetamol and its metabolites at different stages of pregnancy [29]. Small cohorts as in the present study may benefit from PBPK modelling.

The main limitation of the present study was the small sample size. The number of parturients was limited to seven due to challenges in recruiting patients that fulfilled the inclusion criteria. Many parturients had received some other systemic opioid at the start of their labour and were therefore no longer eligible for recruitment to this study. Another limitation of the study was that the dose of HM was decreased from 1.5 to 0.75 and then to $0.5 \mathrm{mg}$ due to nausea and vomiting induced by the higher doses. Due to changes in dose-levels, pharmacokinetic parameters were calculated dose-normalized. The kel and half-life were evaluated for 6 of 7 patients. The last data point available was obtained at the time of birth, and this resulted in a fairly short time interval in the terminal elimination phase in several subjects. In subjects 3, 4 and 6, the time interval was $1.5-1.8$-fold compared with the estimated halflife. In the remaining three subjects, the ratio of the corresponding time interval to half-life was 2.3-3.3.

To conclude, in this pilot study in parturients, distribution and elimination of epidural HM seemed fairly similar to those observed earlier for non-pregnant participants receiving i.v. $\mathrm{HM}$, when absolute bioavailability is assumed to be $100 \%$ for epidural HM. However, as one of the limitations in the study was the short sampling period in the terminal elimination phase, more research is needed to confirm pharmacokinetics of epidural HM in labouring women. Our results suggest that HM crosses the placenta like other opioids. The adverse events of HM were similar to those reported for spinal opioids. Doses lower than $0.5 \mathrm{mg}$ should be used for single epidural dosing of HM hydrochloride to avoid adverse effects. We suggest maximal cumulative dose of $0.5 \mathrm{mg}$ for the duration of the delivery in combination with local anaesthetics.
Acknowledgements Open access funding provided by University of Oulu including Oulu University Hospital. We wish to thank Veli-Pekka Ranta, PhD School of Pharmacy, University of Eastern Finland, for helpful discussions about pharmacokinetic analysis, Marja Vääräsmäki, $\mathrm{PhD}$ Oulu University hospital, for obstetric consultation and the Oulu medical research foundation (Oulu, Finland) for funding.

Authors' contributions Terhi Puhto: Planning, patients' recruitment and clinical implementation, data analysis and writing

Corresponding author

Merja Kokki: Planning, data analysis and writing

Henriikka Hakomäki: Pharmacokinetic analysis, writing, tables and figures

Michael Spalding: Patients recruitment and clinical implementation, writing

Teemu Gunnar: Laboratory analysis, writing

Seppo Alahuhta: Planning, writing

Merja Vakkala: Planning, data analysis and writing, supervisor

Funding information Costs of laboratory analysis in this study have been supported by the Oulu medical Research Foundation (Oulu, Finland).

\section{Compliance with ethical standards}

Conflict of interest The authors declare that they have no conflict of interest.

Open Access This article is licensed under a Creative Commons Attribution 4.0 International License, which permits use, sharing, adaptation, distribution and reproduction in any medium or format, as long as you give appropriate credit to the original author(s) and the source, provide a link to the Creative Commons licence, and indicate if changes were made. The images or other third party material in this article are included in the article's Creative Commons licence, unless indicated otherwise in a credit line to the material. If material is not included in the article's Creative Commons licence and your intended use is not permitted by statutory regulation or exceeds the permitted use, you will need to obtain permission directly from the copyright holder. To view a copy of this licence, visit http://creativecommons.org/licenses/by/4.0/.

\section{References}

1. Ranta P, Spalding M, Kangas-Saarela T, Jokela R, Hollmen A, Jouppila $\mathrm{P}$ et al (1995) Maternal expectations and experiences of labour pain-options of 1091 Finnish parturients. Acta Anaesthesiol Scand 39:60-66

2. Räisänen S, Kokki M, Kokki H, Gissler M, Kramer MR, Heinonen S (2014) The use of epidural analgesia for intrapartum pain relief in publicly funded healthcare. Acta Anaesthesiol Scand 58:291-297

3. DeBalli P, Breen TW (2003) Intrathecal opioids for combined spinal-epidural analgesia during labour. CNS Drugs 17:889-904

4. Schwartz AE, Matteo RS, Ornstein E, Young WL, Myers KJ (1991) Pharmacokinetics of sufentanil in obese patients. Anesth Analg 73: 790-793

5. Chiari A, Eisenach JC (1998) Spinal anesthesia: mechanisms, agents, methods, and safety. Reg Anesth Pain Med 23:357-362

6. Bernards CM (2002) Understanding the physiology and pharmacology of epidural and intrathecal opioids. Best Pract Res Clin Anaesthesiol 16:489-505

7. Draisci G, Frassanito L, Pinto R, Zanfini B, Ferrandina G, Valente A (2009) Safety and effectiveness of coadministration of intrathecal 
sufentanil and morphine in hyperbaric bupivacaine-based spinal anesthesia for cesarean section. J Opioid Manag 5:197-202

8. Murray A, Hagen NA (2005) Hydromorphone. J Pain Symptom Manag 29(5 Suppl):S57-S66

9. Sinatra RS, Levin S, Ocampo CA (2000) Neuroaxial hydromorphone for control of post surgical, obstetric and chronic pain. Semin Anesth 19(2):108-131

10. Rauch E (2011) Intrathecal hydromorphone for cesarean delivery: in search of improved postoperative pain management: a case report. AANA J 79:427-432

11. Chestnut DH, Choi WW, Isbell TJ (1986) Epidural hydromorphone for postcesarean analgesia. Obstet Gynecol 68:65-69

12. Henderson SK, Matthew EB, Cohen H, Avram MJ (1987) Epidural hydromorphone: a double-blind comparison with intramuscular hydromorphone for postcesarean section analgesia. Anesthesiology 66:825-830

13. Dougherty TB, Baysinger CL, Henenberger JC, Gooding DJ (1989) Epidural hydromorphone with and without epinephrine for post-operative analgesia after cesarean delivery. Anesth Analg 68: 318-322

14. Miners JO, McKinnon RA, Mackenzie PI (2002) Genetic polymorphisms of UDP-glucuronosyltransferases and their functional significance. Toxicology 181-182:453-456

15. Bouwmeester NJ, Anderson BJ, Tibboel D, Holford NH (2004) Developmental pharmacokinetics of morphine and its metabolites in neonates, infants and young children. Br J Anaesth 92:208-217

16. Saari TI, Ihmsen H, Mell J, Fröhlich K, Fechner J, Schüttler J, Jeleazcov C (2014) Influence of intensive care treatment on the protein binding of sufentanil and hydromorphone during pain therapy in postoperative cardiac surgery patients. Br J Anaesth 113: $677-687$

17. Apgar V (1955) The role of anesthesiologists in reducing neonatal mortality. N Y State J Med 55:2365-2368

18. Amiel-Tison C, Barrier G, Shnider SM, Levinson G, Hughes SC, Stefani SJ (1982) A new neurologic and adaptive capacity scoring system for evaluating obstetric medications in full-term newborns. Anesthesiology 56:340-350

19. Hill HF, Coda BA, Tanaka A, Schaffer R (1991) Multiple-dose evaluation of intravenous hydromorphone pharmacokinetics in normal human subjects. Anesth Analg 72:330-336
20. Ansari J, Carvalho B, Shafer SL, Flood P (2016) Pharmacokinetics and pharmacodynamics of drugs commonly used in pregnancy and parturition. Anesth Analg 122:786-804

21. Collins JJ, Geake J, Grier HE, Houck CS, Thaler HT, Weinstein HJ, Twum-Danso NY, Berde CB (1996) Patient-controlled analgesia for mucositis pain in children: a three-period crossover study comparing morphine and hydromorphone. J Pediatr 129:722-728

22. Jeleazcov C, Ihmsen H, Saari TI, Rohde D, Mell J, Frohlich K et al (2016) Patient-controlled analgesia with target-controlled infusion of hydromorphone in postoperative pain therapy. Anesthesiology 124:56-68

23. Brose WG, Tanelian DL, Brodsky JB, Mark JB, Cousins MJ (1991) CSF and blood pharmacokinetics of hydromorphone and morphine following lumbar epidural administration. Pain 45:11-15

24. Breivik H, Niemi G (2001) Does adrenaline improve epidural bupivacaine and fentanyl analgesia after abdominal surgery? Anaesth Intensive Care 29:436-437

25. Anderson GD (2005) Pregnancy-induced changes in pharmacokinetics: a mechanistic-based approach. Clin Pharmacokinet 44:9891008

26. Anderson BJ, Holford NHG (2018) Negligible impact of birth on renal function and drug metabolism. Paediatr Anaesth 11:10151021

27. Swenson JD, Owen J, Lamoreaux W, Viscomi C, McJames S, Cluff $\mathrm{M}$ (2001) The effect of distance from injection site to the brainstem using spinal sufentanil. Reg Anesth Pain Med 26:306-309

28. Weiniger CF, Carvalho B, Stocki D, Einav S (2017) Analysis of physiological respiratory variable alarm alerts among laboring women receiving remifentanil. Anesth Analg 124:1211-1218

29. Mian P, Van denAnker JN, Van Calsteren K, Annaert P, Tibboel D, Pfister M et al (2020) Physiologically based pharmacokinetic modeling to characterize acetaminophen pharmacokinetics and $\mathrm{N}$ acetyl-p-benzoquinone imine (NAPQI) formation in non-pregnant and pregnant women. Clin Pharmacokinet 59:97-110

Publisher's note Springer Nature remains neutral with regard to jurisdictional claims in published maps and institutional affiliations. 